\title{
Diagnostic Findings in a Confirmed Outbreak of Brucella ovis Infection in a Traditional Sheep Farm in Sicily (South-Italy)
}

\author{
Paola Galluzzo ${ }^{1,2}{ }^{\mathbb{D}}$, Sergio Migliore ${ }^{1, *} \mathbb{*}$, Silvana Cascio ${ }^{3}$, Santino Barreca ${ }^{1}$, Marilena Alfano ${ }^{1}$, \\ Antonina Tagliarini ${ }^{1}$, Anna Candela ${ }^{1}$, Chiara Piraino ${ }^{1}$, Lucia Galuppo ${ }^{1}$, Lucia Condorelli ${ }^{1}$, Hany A. Hussein ${ }^{1} \oplus$, \\ Manuela Tittarelli ${ }^{4}$ and Giuseppina Chiarenza ${ }^{1}$ \\ 1 Istituto Zooprofilattico Sperimentale della Sicilia "A. Mirri", 90129 Palermo, Italy; \\ paola.galluzzo@izssicilia.it (P.G.); santinobarreca@gmail.com (S.B.); marilena.alfano@izssicilia.it (M.A.); \\ antonietta.tagliarini@izssicilia.it (A.T.); anna.candela@izssicilia.it (A.C.); chiara.piraino@izssicilia.it (C.P.); \\ galuppolucia@gmail.com (L.G.); luciacond1980@gmail.com (L.C.); hany.ahmed@izssicilia.it (H.A.H.); \\ giuseppina.chiarenza@izssicilia.it (G.C.) \\ 2 Dipartimento Scienze e Tecnologie Biologiche Chimiche e Farmaceutiche, University of Palermo, \\ 90133 Palermo, Italy \\ 3 Azienda Sanitaria Provinciale di Trapani, 91100 Trapani, Italy; silvanacascio@asptrapani.it \\ 4 Istituto Zooprofilattico Sperimentale dell'Abruzzo e del Molise "G. Caporale", 64100 Teramo, Italy; \\ m.tittarelli@izs.it \\ * Correspondence: sergio.migliore@izssicilia.it
}

Citation: Galluzzo, P.; Migliore, S.; Cascio, S.; Barreca, S.; Alfano, M.; Tagliarini, A.; Candela, A.; Piraino, C.; Galuppo, L.; Condorelli, L.; et al. Diagnostic Findings in a Confirmed Outbreak of Brucella ovis Infection in a Traditional Sheep Farm in Sicily (South-Italy). Pathogens 2021, 10, 1472. https://doi.org/10.3390/ pathogens10111472

Academic Editors: Gema Álvarez García, Esther Collantes Fernández and Laura del Rio Alonso

Received: 23 September 2021 Accepted: 10 November 2021 Published: 12 November 2021

Publisher's Note: MDPI stays neutral with regard to jurisdictional claims in published maps and institutional affiliations.

Copyright: () 2021 by the authors. Licensee MDPI, Basel, Switzerland. This article is an open access article distributed under the terms and conditions of the Creative Commons Attribution (CC BY) license (https:// creativecommons.org/licenses/by/ $4.0 /)$.

\begin{abstract}
Aim of this study is to report a laboratory investigation performed following the isolation of Brucella ovis, causing ovine epididymitis, in a traditional sheep farm in Sicily (South Italy). This disease represents a newly emerging risk for Italian livestock and is listed among diseases of EU priority (EU Reg 2016/429). Blood samples from 56 rams and 143 ewes were analyzed by both Enzyme-Linked Immunosorbent Assay (ELISA) and Complement Fixation Test (CFT). Genital swabs from all rams and 15 lactating ewes were collected to perform real-time PCR. Eighteen serologically positive rams were slaughtered and postmortem-inspected. Samples of testicle, epididymis, lymph nodes, and urine were also collected in order to perform microbiological, molecular, and histopathological analysis. Twelve slaughtered rams showed anatomo-pathological lesions. Real-time PCR for B. ovis BOV_A0504 gene was positive for 13 testicles and epididymis and 11 urine while B. ovis was isolated from epididymis and testicles of 7 slaughtered rams. This is the first exhaustive laboratory report of a microbiological, molecular, and serological pattern of the disease in sheep in Italy. Despite the impact on health and animal welfare, the epidemiology of B. ovis infection is still unknown, particularly in our country where the disease is considered endemic.
\end{abstract}

Keywords: Brucella ovis; ovine epididymitis; rams; ewes; diagnosis

\section{Introduction}

Brucella ovis is a Gram-negative and naturally rough $(\mathrm{R})$ bacterium belonging to the Brucella genus and is the causative agent of ovine epididymitis [1]. The disease affects sheep exclusively, causing genital lesions and overall reproductive failure. The main clinical manifestation in rams is epididymitis (either uni or bilateral), orchitis, and infertility [2]. Despite being nominated as 'ovine epididymitis', B. ovis infection can also induce clinical signs in ewes such as placentitis, abortion, and stillbirth. For this reason, the term 'Brucella ovis infection' is preferred, as epididymitis in rams can be caused by a large variety of pathogenic agents $[2,3]$.

The disease is mainly transmitted via mating, ewes act as a passive reservoir. The occurrence of infection in a healthy farm is linked to the entry of infected animals: this negatively affects the fertility rate of the flock which might remain reduced even after eradication of the diseased animals [4]. Rams generally develop a subacute or chronic infection and shed B. ovis intermittently with semen, genital secretions, and urine for at 
least $2-4$ years. Lesions were observed in $20-50 \%$ of naturally infected rams, while in artificially infected heads, the percentage of rams with lesions varies from $30 \%$ to $50 \%[2,3]$.

The prevalence and incidence in naïve sheep populations not subjected to prophylaxis are usually very high, especially when the disease is first reported in free regions, with $2-67 \%$ of rams and $9-50 \%$ of total animals being infected. Manifestation of clinical lesions in infected rams ranges from 20 up to $50 \%$ and abortion from 25 up to $60 \%$ of pregnant ewes $[2,3,5]$.

B. ovis infection was reported in sheep farming worldwide but to date, the real distribution of B. ovis infection in the world is largely unknown (EFSA). Eradication programs/plans are not compulsory and successful conclusions of eradication campaigns have never been reported [3].

Unlike the other species of Brucella, B. ovis is not classified as a zoonosis and although it is considered to have a less severe health impact than the other species affecting ruminants, it is a cause of significant losses related to hypofertility and related concerns due to the impact on the genetic selection in the farm [6]. Recently, B. ovis infection has been assessed according to the criteria of the Animal Health Law (AHL), Regulation (EU) No 2016/429 and it was considered eligible to be listed (Commission Delegated Regulation (UE) 2018/1629) for control measures as laid down in Article 5 (3) of the AHL [7] (EU, 2021).

B. ovis infection doesn't show peculiar, pathognomonic clinical symptoms and often the disease is subclinical and could circulate in the flock without suspicion. Several diagnostic tests are available today, including those recognized by OIE and EU regulations [8]. Other bacteria, such as Actinobacillus seminis, Histophilusovis, Haemophilus spp., Corynebacterium pseudotuberculosis ovis, Chlamydophila abortus, or B. melitensis are responsible for ovine epididymitis and more than $50 \%$ of the cases related to B. ovis infection normally do not show any visible lesion to the epididymis [9]: this makes it difficult to suspect just by clinical examination, the presence of the disease.

Diagnosis of $B$. ovis infection is based on clinical observation of genital organs, or with the help of laboratory tests such as antibodies detection through serological tests (CFT, ELISA, etc), bacterial isolation from semen and urines, or molecular tests (PCR) to detect DNA of the pathogen [10]. For certainty in the diagnosis, it is appropriate to repeat the sampling as the excretion is often intermittent. Although the Enzyme-Linked Immunosorbent Assay (ELISA) sensitivity is higher than Complement Fixation Test (CFT) the latter is the most widely used for B. ovis diagnosis due to its simplicity, cost, and lack of internationally recognized standardized ELISA assay. Therefore, CFT remains the most suitable test to certify individual animals before handling, even for international trade [9].

Despite the renewed attention of the European legislator on B. ovis infection, the information about the disease detection in the field remains scanty and to great extent incomplete, especially in traditional sheep farming where the infection is underestimated due to its subclinical occurrence.

In the present study, we described the diagnostic findings observed in an outbreak of B. ovis infection in a traditional sheep farm in Sicily in order to provide more details for rapid and proper disease detection.

\section{Results}

\subsection{Serological Analysis}

The serological diagnosis was carried out using both CFT and ELISA tests in order to assess the efficacy of these two methods and to have more data for proper evaluation of $B$. ovis infection in the examined farm. Anti-B. ovis antibodies were detected in 29 sera $(51.8 \%)$ of rams by CFT assay whereas ELISA confirmed a larger number of samples, highlighting 35 rams $(62.5 \%)$ positive to $B$. ovis.

In contrast, the 143 sampled ewes showed a lower seroprevalence than rams with $5(3.5 \%)$ and $7(4.9 \%)$ heads positive to anti-B. ovis antibodies detected by CFT and ELISA, respectively (Figure 1). Despite ELISA appearing more sensitive, the two tests used revealed good agreement with a concordance of $88 \%$ and the K Cohen of 0.757 . 


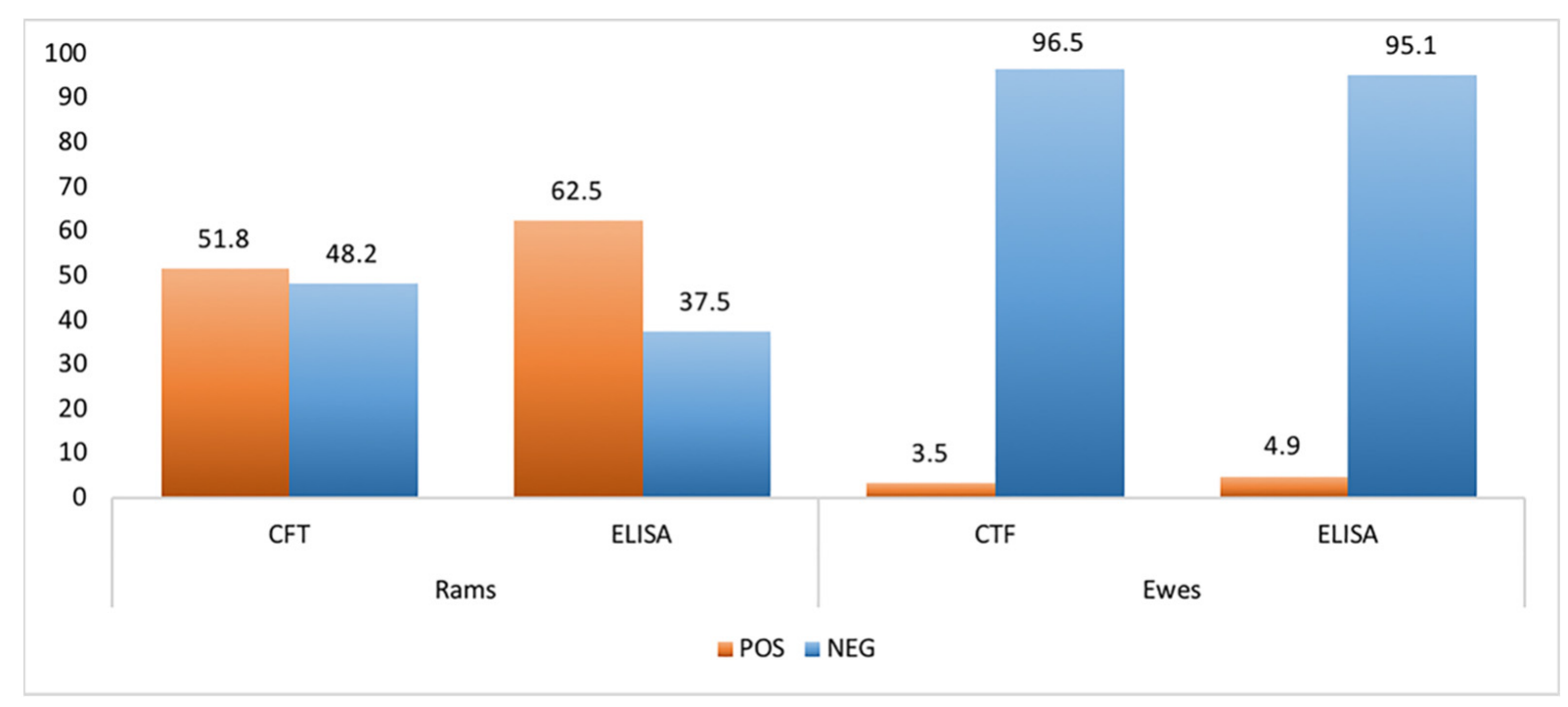

Figure 1. Serological results were obtained by Complement Fixation Test (CFT) and Enzyme-Linked Immuno Assay (ELISA) tests to evaluate the presence of anti-B. ovis antibodies in rams and ewes sera.

\subsection{Ante-Mortem and Post-Mortem Examination}

Clinical examination and testicular palpation revealed the presence of specific lesions located in the epididymis and/or testicle. A total of 15 rams showed lesions (epididymitis and/or orchitis) and no other intercurrent pathologies were observed. In agreement with the owner and thanks to the support of the Veterinary Service of Trapani symptomatic and serological positive rams (18) were regularly slaughtered and inspected. Out of the total of 18 rams, 6 didn't show lesions while the remaining $12(66.67 \%)$, showed testicular asymmetry, hardness related to atrophy or hypertrophy, and epididymitis (Figure 2).

Anatomo-pathological changes were mainly identified in epididymitis, in the tunica vaginalis, and the parenchyma of the testicles: change varied from moderate to marked increase in the volume and modification in the consistency of the organ. The epididymal changes were generally unilateral, and the epididymal tail was more often affected than the head or the body (Figure 2).

\subsection{Histopathological and Immunohistochemical Findings}

Histological examination of the reproductive system tissues revealed evident epididymitis, ampollitis, and seminal vesiculitis on 11 rams (61.1\%). The epididymitis showed focal pictures and could be classified as mild to severe. Histological lesions were characterized by mild to moderate focal accumulations of scattered lymphocytes and plasma cells or as perivascular sleeves in the interstitial connective tissue (Figure 3a,b). Focal accumulations of lymphocytes, plasma cells, and neutrophils with necrotic debris have also been observed in the lumen of the spermatic ducts. Accumulation of cellular debris, in some cases, resulted in the complete obstruction of the epididymis with subsequent abscess formation. Immunohistochemical staining revealed B. ovis bodies in the epididymal lesions. Brucella-specific staining was also detected within the cytoplasm of interstitial macrophages, epithelial ductal elements, macrophages, and neutrophils (Figure $3 c, d$ ). Positive cytoplasmic immunohistochemical staining was very intense in epithelial cells, especially lining the epididymal ducts; while extracellular brucellae were observed in the interstitium and spaces between the epididymal ducts.

\subsection{Molecular Findings}

Despite the official diagnosis in Italy only being provided for serological tests and clinical examination of animals, real-time PCR was performed on genital swabs and milk samples from living animals and tissues from slaughtered rams, in order to improve our data. The real-time PCR for B. ovis was based on a unique genetic locus, BOV_A0504, 
which was identified by in silico comparisons with other Brucellae and confirmed on several reference strains by Hinić and colleagues [11].

BOV_A0504 gene fragment for B. ovis was detected in 18 (32.1\%) of the 56 preputial swabs.

Regarding samples collected from 15 dairy ewes, milk samples and vaginal swabs showed the presence of $B$. ovis target gene only in 6 out of 15 animals. Particularly positivity was detected in $6(40 \%)$ and $3(20 \%)$ of milk and vaginal swabs, respectively. With regard to molecular investigations carried out on tissue, a specific $B$. ovis gene fragment was confirmed in $13(72.2 \%)$ testicles and epididymis and in $11(61.1 \%)$ urine samples. Samples reported ct values ranging from 27.5 to 37 .
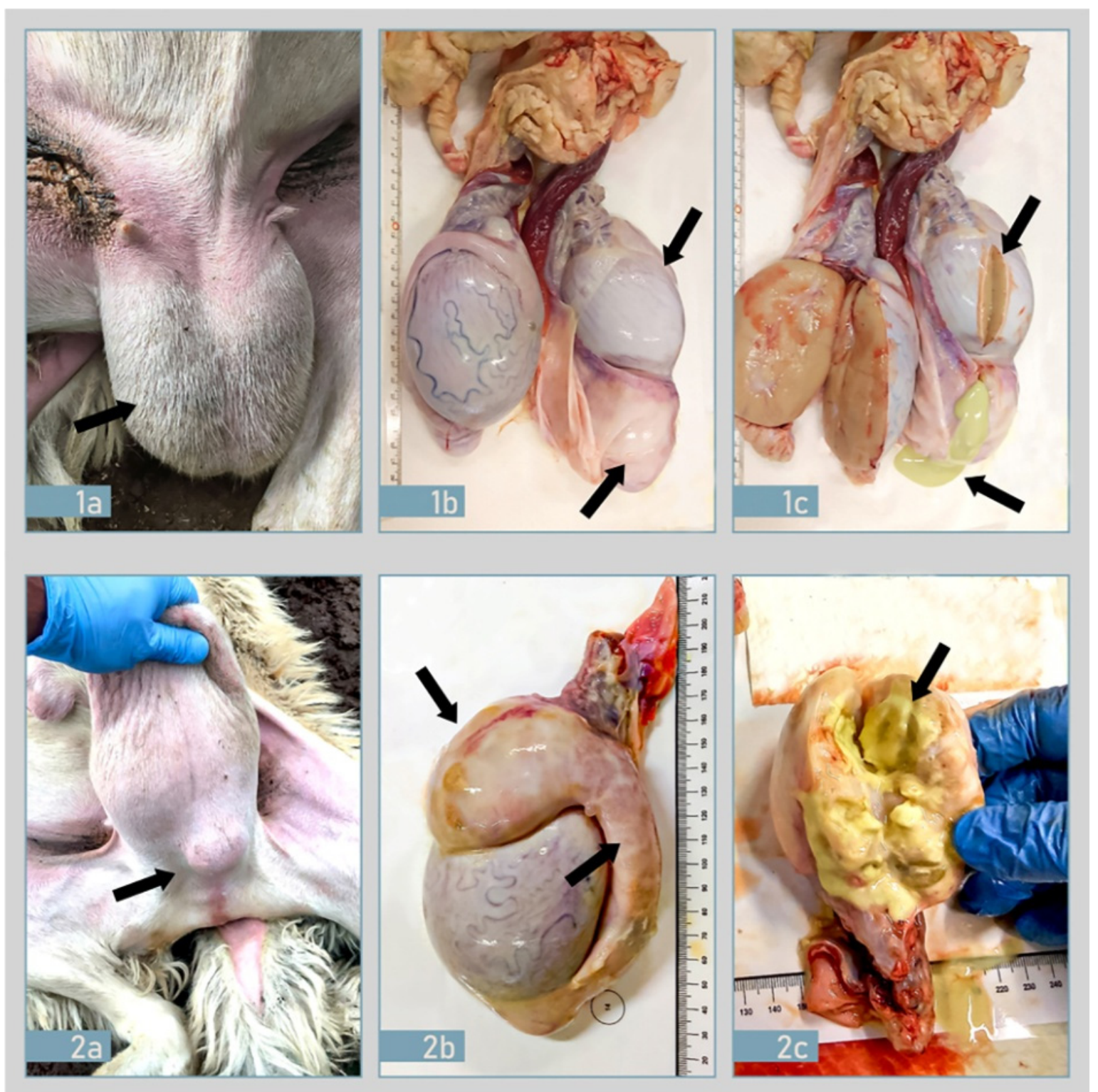

Figure 2. Anatomo-pathological findings in two different rams $(\mathbf{1}, \mathbf{2})$ naturally infected with B. ovis. (1a) Genital organs appearance with testicular asymmetry; (1b) Right testis showed atrophy with an absence of vascularization, diffuse fibrosis, and thickness of tunica vaginalis firmly adhered to the testis, and enlargement of the tail of epididymis in comparison with apparently normal left testis; (1c) Right testis atrophy with the tail of epididymis filled with yellowish caseous viscous fluid (purulent exudate). (2a) Subcutaneous mass on external examination; (2b) body and tail of left epididymis are severally increased in size with fibrosis/adherence of tunica vaginalis and epididymal abscess. (2c) Epididymis abscess: the body of epididymis is increased in size with a focal area in cut surface with yellowish caseous material. 


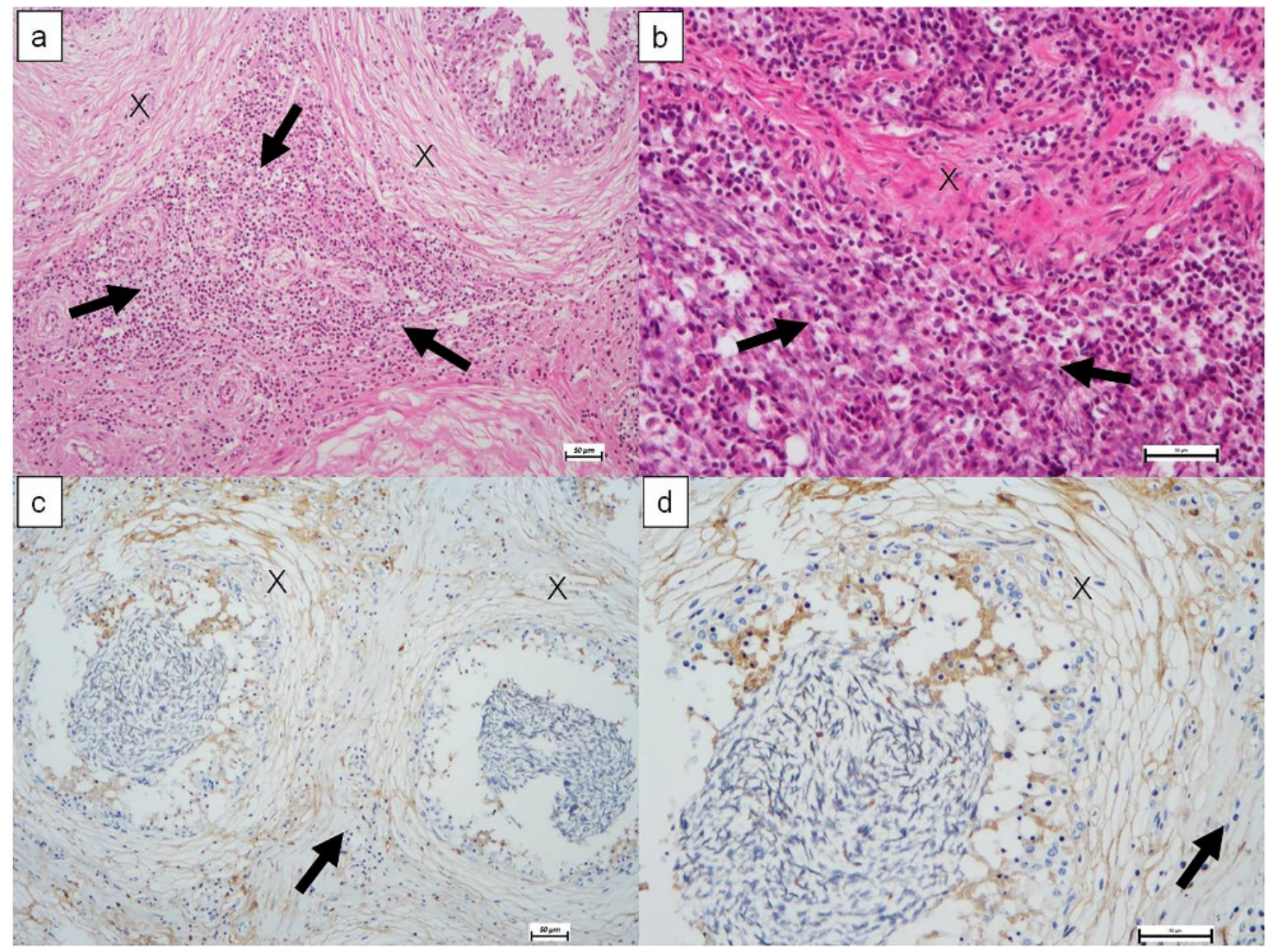

Figure 3. (a): Epididymis $(X)$ with focal accumulations of lymphocytes, plasma cells, and neutrophils with necrotic debris (arrow); (b): surrounding interstitium characterized by mixed leukocytic infiltrate, predominantly macrophages (arrow), Haematoxylin-eosin stain, (c,d): epididymal ducts $(\mathrm{X})$ containing B. ovis antigen (brown particles) and surrounded by a mantle of neutrophils, lymphocytes, plasma cells and macrophages (arrow). Both sections are stained for immunohistochemistry using anti-B. ovis antibody and hematoxylin counterstain. Bar size $50 \mu \mathrm{m}$.

\subsection{Microbiological Findings}

Testicles, epididymis, lymph nodes, and urine samples collected from the 18 slaughtered rams were subjected to microbiological investigation in order to isolate B. ovis strains. No Brucella spp. was isolated from lymph nodes and urine samples. Colonies attributable to Brucella spp. were identified in testes and epididymis of 7 animals (38.9\%). Isolated bacterial colonies were subcultured onto blood agar plates where they appeared transparent, non-hemolytic, and rather small in size. On Gram staining, all isolated colonies appeared as small Gram-negative coccobacilli. At biochemical tests strains were negative for growth in MacConkey agar, growth in $\mathrm{CO}_{2}$ atmosphere, oxidase test, mobility, urease and $\mathrm{H}_{2} \mathrm{~S}$ production, glucose oxide fermentation. Contrary, isolated strains tested were positive for catalase, growth in presence of $50 \mu \mathrm{g} / \mathrm{mL}$ both basic fuchsin and thionin. No agglutination was observed with Brucella A and M anti-serum and isolated strains didn't grow during phages characterization. All tests led to strain identification such as B. ovis.

All isolated strains were confirmed as B. ovis by AMOS-PCR. The PCR provided the characteristic 976-bp amplicon for B. ovis.

The 7 rams from which B. ovis was isolated were also positive for antibodies screening, DNA detection, and showed evident pathological changes of the reproductive system.

\section{Discussion}

In this study, we showed for the first time in Italy, an exhaustive diagnostic report on B. ovis infection in a traditional Sicilian sheep farm. Despite the impact on health and animal welfare, information about the distribution and the diagnostic findings of $B$. ovis 
infection remains scarce and largely incomplete in most of the world, probably due to its non-pathogenicity to humans than other zoonotic Brucella spp. strains [12]. For this reason, we reported a complete clinical and laboratory profile of an outbreak identified in Sicily. Laboratory data relating to serological tests, isolation of the strain, bimolecular assay, and histological pattern were reported in order to provide a complete picture as the ovine epididymitis spread in a flock. We found a high seroprevalence in the tested rams $(62.5 \%$ and $51.8 \%$ by ELISA and CFT assays respectively) in contrast to the lower prevalence detected in the ewes (3.5\% and $4.9 \%$ by ELISA and CFT respectively). In our experience, differently, than other case reports [13-15], a high percentage (66.67\%) of seropositive rams showed clinical signs and typical lesions.

To date, B. ovis infection in Sicily, as well as in Italy, is not well investigated and only a preliminary study on the spread of infection conducted on 942 rams belonging to 163 Sicilian farms reported a seroprevalence of $10 \%$ at the animal level [16]. In Italy, the disease was described for the first time in two rams in Lombardia in 1994 [15]. In relation to the reports drawn up by the OIE from 2013 to date this disease has never been notified officially in Italy (Figure 4).

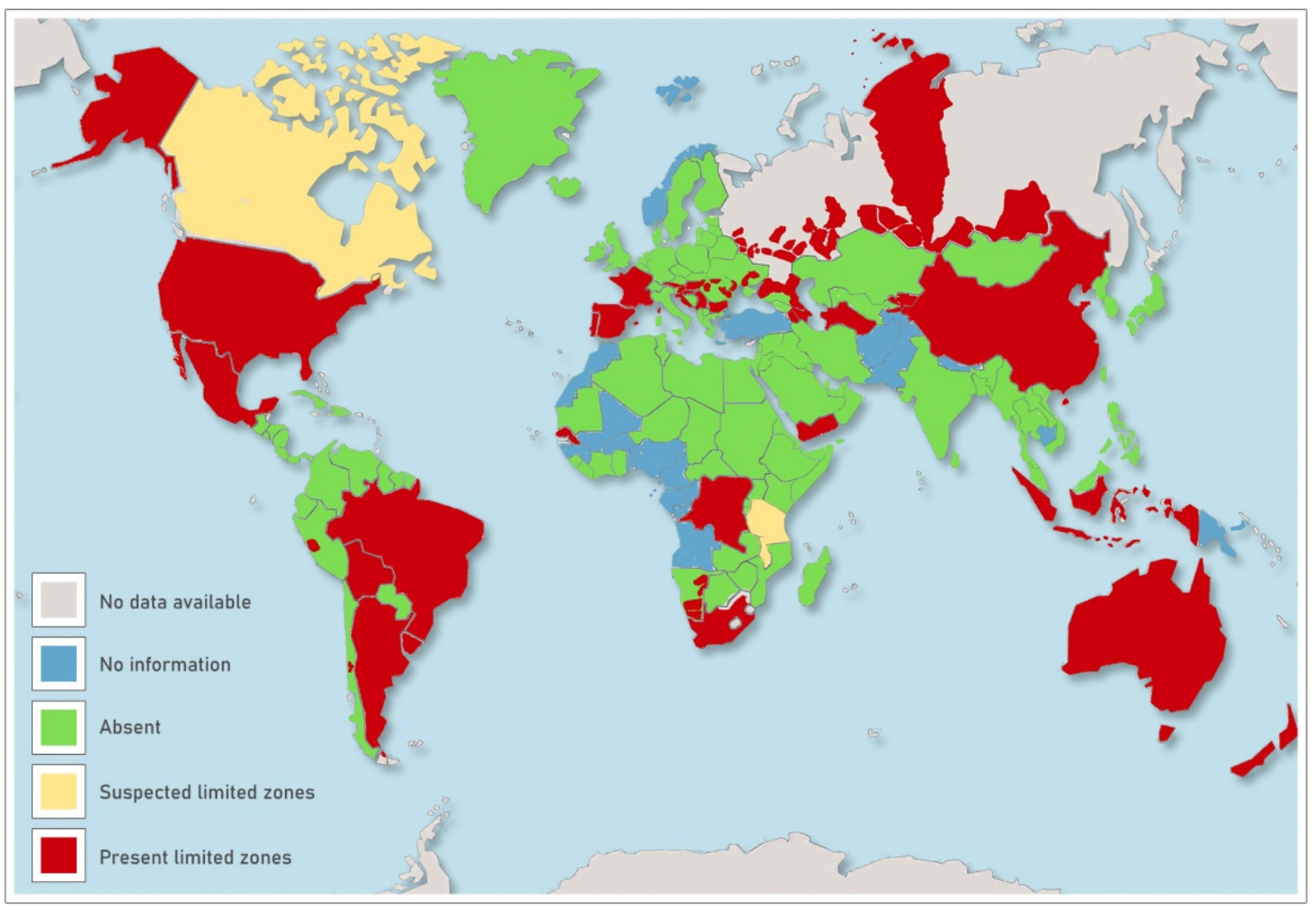

Figure 4. Countries reporting Brucella ovis infection worldwide.

Nevertheless, the isolation of $B$. ovis was also reported by local clinicians from sheep in the Trentino Alto-Adige, Campania, Marche [17,18], Piedmont, Abruzzi, and Lazio regions suggesting a significant presence of the infection in the Italian sheep population [12].

Different approaches for surveillance of the disease is reported from America, Asia, and Australia: data on seroprevalence were published in the livestock population of Wyoming [18] (0.53\%), Idaho and Oregon (14.9\%), Utah (27.1\%), New Mexico (67.5\%) and $10.0 \%$ in rams across Colorado, Wyoming, and Utah $(10 \%)[19,20]$. In Brazil, B. ovis seroprevalence ranging from $0.72 \%$ up to $2.89 \%$ [21,22]. In Europe, around $10 \%$ of seroprevalent animals were reported in New South Wales [5] and in the Basque Country in Spain [23], 
while a higher percentage was described in Serbia (29.8\%) [24] and France (53.7\% and $37.2 \%$ by ELISA and CFT assays respectively [25].

B. ovis natural infection has never been reported in wildlife, thus, the prevalence in other species is considered not relevant [26].

Sergeant [5], noted that the flock prevalence (percentage of flocks containing seropositive rams) was influenced by breed ( $9.1 \%$ for Merino flocks that were significantly lower than British-breed flocks $43.8 \%$, and mixed-breed flocks $46.7 \%$ ).

We reported a severe outbreak in the Sicilian Valle del Belìce dairy sheep breed confirming that the susceptibility to infection may vary among breeds of sheep. A study identified risk factors for ovine epididymitis to be the average age of rams in flocks, farms larger than $5 \mathrm{~km}^{2}$, and the lack of lambing paddocks [22].

Frequent isolation of B. ovis from the urine of slaughtered animals, from placentomes (cotyledon plus caruncle), and abomasal fluid confirms that in natural infection the microorganism may contaminate the environment through several biological fluids as well as proves that venereal route is not the only way of transmission [27]. Our molecular biology data were in agreement with these observations. In fact, in addition to identifying samples of genital swabs by real-time PCR, the specific DNA fragment for B. ovis was also detected in milk and urine samples. In particular, we found B. ovis DNA in $40 \%$ and $61.1 \%$ of milk and urine samples, respectively. Unfortunately, the pathogen has not been isolated probably due to the complexity of these matrices, which although widely used in diagnosis is very rich in fats. Although a selective medium was used, the long time needed for the isolation (six weeks) of this pathogen, often favors the growth of other microorganisms (especially molds) and makes the Brucella spp. isolation difficult.

Our positive PCR data on milk samples are in agreement with what was reported by Grillò et al. in 1999 [28]. Furthermore, those authors reported that in three sheep, artificially infected with $B$. ovis, mammary infection lasted for the whole lactation season till the next one. The persistent excretion of $B$. ovis in milk, with the consequent risk of perinatal transmission to the unweaned lambs, with the development of latent infections, are believed to play an important role in maintaining infection in the flock even without the role of rams [4].

However the OIE manual considers CFT as the most effective test, in this study 2 rams were diagnosed negative for CFT assay, but they were positive for ELISA and PCR and had evident both macroscopic and histopathological lesions. These data highlight the great importance of the use and comparison of more than one diagnostic method in order to verify true positives.

Although B. ovis infection was described worldwide, its control is still based on farm management including vaccination with the attenuated B. melitensis strain Rev. 1 vaccine (where permitted). In other countries test and culling are applied, but complete eradication is extremely difficult to achieve and there is no report of a successful eradication campaign.

Usually, culling of symptomatic and positive rams is the only control measure applied. However, breeder often decides not to cull the seropositive rams because they are genetic improver in their breed and carrier of scrapie resistant genotype ARR/ARR. For this reason, any eradication measure should consider the status of each sheep population to preserve genetic and biodiversity together with disease control [29]. Despite, the disease has never been reported in Belgium, Denmark, Finland, Greece, Ireland, Luxembourg, Portugal, Sweden, the Netherlands, and the UK [30], the disease is not included among those diseases where mandatory eradication is requested. Thanks to the introduction of Reg. 429/2016, in force since April 2021, and with the application of the Commission Implementing Regulation (EU) 2018/1882, ovine epididymitis will be officially recognized among the MS as a "moderate risk disease" and addressed to specific surveillance and control measures to prevent its spread among MS or its entry into the EU.

The new regulation does not concern any special requirements for internal movement of the flocks but obliges all Member States (MS) to organize veterinary surveillance and laboratory certification if rams are moved between MS. 


\section{Materials and Methods}

\subsection{Anamnestic Data}

The outbreak was identified in a traditional sheep farm, all ewes belonged to Valle del Belice breed. The farm was located in the province of Trapani (Sicily) a district that concerns above 480 farms and a total population of 89,096 heads (latest census date back 2020) (IZS Teramo-Anagrafe Zootecnica) (https:/ / www.vetinfo.it, accessed on 10 December 2020). In this area, livestock is conducted in a semi-extensive and extensive farming system with common grazing.

The farm counted a total number of 900 heads, of which 58 rams. The owner asked for veterinary consultation due to the presence of unusual swelling of the scrotum in several rams. However, problems of decreased fertility, abortion, or significant neonatal mortality are not reported by the owner.

\subsection{Serological Analysis}

Blood samples without anti-coagulant were collected from 56 rams and 143 ewes into a $10 \mathrm{mLvacuum}$ tube. Samples were allowed for clotting then were centrifuged $(1500 \mathrm{rpm}$ for $10 \mathrm{~min}$ ) to recover the sera which were stored at $-20{ }^{\circ} \mathrm{C}$ until tested. All sera were analyzed by two different tests: Enzyme-Linked Immuno Assay (ELISA) and Complement Fixation Test (CFT).

ELISA test was performed using a commercial kit (IDEXX Brucella ovis) applied as suggested for surveillance screening and the assay was done following the manufacturer's instructions. As recommended samples were considered positive when the SP (sample-topositive) $\%$ was above or equal to 45 , while samples with SP\% under 45 were interpreted as negative.

Complement Fixation Test was carried out by utilizing the protocol published in the OIE Manual [9]. Sera giving a titer equivalent to $50 \mathrm{ICFTU} / \mathrm{mL}$ (International CFT units) or more were considered positive.

The sample size was calculated considering a minimum expected prevalence of $2 \%$ (EFSA), with a confidence level of 95\%, according to Winepi software (http:/ / www.winepi. net/, accessed on 10 December 2020).

To evaluate CFT and ELISA tests agreement the Cohen's kappa was calculated using GraphPad calculator (https: / / www.graphpad.com, accessed on 10 December 2020).

\subsection{Molecular Analysis}

Simultaneously to serological investigations, preputial swabs from all rams were collected. In addition, vaginal swabs and milk samples from 15 lactating ewes were also sampled.

Genomic DNA was extracted from tissues and milk using the commercial kit (Purelink Genomic DNA, Invitrogen, Thermo Fisher Scientific, Waltham, MA, USA) following the tissue protocol provided by the manufacturer. Urine samples were centrifuged at $13,000 \mathrm{rpm}$ for $30^{\prime}$, the precipitated pellet was resuspended in $200 \mu \mathrm{L}$ of 1 X PBS (Phosphate Buffered Saline), while genital swab samples were immersed shook in $200 \mu \mathrm{L}$ of 1X PBS: in both cases, the bacterial culture protocol provided by the manufacturer was followed [11]. Real-time PCR was performed to amplify a unique genetic locus, BOV_A0504. Real-time amplification was carried out in a total reaction volume of $25 \mu \mathrm{L}$ containing $10 \mu \mathrm{L}$ SSo advanced Universal Probes Supermix (Bio-Rad, Hercules, CA, USA), $0.5 \mu \mathrm{L}$ of each primer $(10 \mathrm{mM})$ and TaqMan probe $(10 \mathrm{mM}), 2 \mu \mathrm{L}$ TaqMan ${ }^{\circledR}$ Exogenous Internal Positive Control mix and $0.5 \mu \mathrm{L}$ IPC template (Applied Biosystems, Thermo Fisher Scientific, Waltham, MA, USA) and about $100 \mathrm{ng} / \mu \mathrm{L}$ of DNA. The real-time PCR was performed using the CFX96 Touch Real-Time PCR Detection System (Bio-Rad). The instrumented program included an initial denaturation of $3 \mathrm{~min}$ at $95^{\circ} \mathrm{C}$ followed by 40 cycles of amplification that included a denaturation step at $95^{\circ} \mathrm{C}$ for $10 \mathrm{~s}$ and an annealing/extension step at $60{ }^{\circ} \mathrm{C}$ for $30 \mathrm{~s}$. All samples with a $\mathrm{Ct}$ less than 38 were considered positive for $B$. ovis. All runs included a 
positive sample of B. ovis (REO 156) provided by the Italian National Reference Center for Brucellosis and a negative (DNAase/RNAase free water) control.

\subsection{Clinical Examination and Sampling}

Following serological and biomolecular investigations on sera and swabs respectively, a clinical examination by testicular palpation was performed in all rams. Therefore, the owner was agreed to eliminate all animals simultaneously positive to serological and molecular tests and clinical examination in order to clear the farm from animals at risk.

Eighteen positive rams were regularly slaughtered in an authorized slaughterhouse and post mortem inspection of the reproductive tract was performed.

Samples of testicle and epididymis from the 18 rams were collected in order to perform microbiological, molecular, and histopathological analyzes. In addition, 18 urine samples for molecular analysis were also collected.

\subsection{Histology-Hematoxylin \& Eosin Staining}

A portion of pathological tissue of epididymis, testicle, and related lymph nodes $(0.5 \times 2 \times 4 \mathrm{~cm})$ was fixed in $10 \%$ buffered formalin. Serial sections of paraffin-embedded tissues of $4 \mu \mathrm{m}$ thickness were cut using a microtome and set on slides treated with silane (3-aminopropyl-trieossi-silane) in order to avoid detachment during staining. The preparations obtained were dried overnight in an oven at $37^{\circ} \mathrm{C}$. It was proceeded with dewaxing by xylene for $20 \mathrm{~min}$. After a descending alcohol series $\left(100^{\circ}, 95^{\circ}, 75^{\circ}\right.$, and $\left.50^{\circ}\right)$, slides were washed in distilled water and then stained with hematoxylin and eosin. This was followed by the ascending scale of alcohols $\left(50^{\circ}, 75^{\circ}, 95^{\circ}\right.$, and $\left.100^{\circ}\right)$ and clarification in xylene. After this phase, the slides were mounted in acrylic mounting medium (Eukitt ${ }^{\circledR}$, O. Kindler GmbH, Baden-Württemberg, Germany).

\subsection{Immunohistochemistry (IHC)}

Immunohistochemical studies were performed on formalin-fixed paraffin-embedded pathological tissue, where a flogistic infiltrate was observed (mainly epididymis). Serial sections (4 $\mu \mathrm{m}$ thick) on glass slides were washed in xylene and hydrated in decreasing concentrations of alcohol. For antigen retrieval, the slides were heated in sodium citrate solution ( $\mathrm{pH} 6.0$ ) at $96{ }^{\circ} \mathrm{C}$ for $20 \mathrm{~min}$. Endogenous peroxidase activity was quenched with $3 \%$ hydrogen peroxide in methanol for $30 \mathrm{~min}$. Then the slides were treated with $1 \%$ bovine serum albumin (BSA) for $30 \mathrm{~min}$ and incubated for $1 \mathrm{~h}$ at room temperature in the presence of 0.1\% BSA with polyclonal rabbit, antibody anti-Brucella spp. (Byorbit), diluted 1:200 in $0.01 \mathrm{M}$ PBS. In the end, the sections were treated for $30 \mathrm{~min}$ with secondary biotinylated immunoglobulin anti-rabbit antibody (DAKO, LSAB Kit, K0690, Denmark). The sections were then incubated with a streptavidin-horseradish peroxidase conjugate for $1 \mathrm{~h}$, followed by chromogen 3-3' diaminobenzidine tetrahydrochloride for $1 \mathrm{~min}$, and counterstained with Mayer's hematoxylin. The specific primary antibody was replaced with PBS in tissue sections used as negative controls. The DAB reaction developed a brown precipitate, when positive. Images of stained slides were captured by Leica DMR microscope equipped with a Leica DFC 320 digital camera and analyzed using digital image analysis (Nikon NIS Br, Nikon Instruments Europe BV, Amsterdam, The Netherlands).

\subsection{Bacteriological Analysis and B. ovis Identification}

Testicles, epididymis, lymph nodes, and urine of the 18 slaughtered rams were collected to perform a microbiological examination in order to isolate B. ovis.

Urine samples were streaked directly onto Brucella agar (modified Farrell's selective medium) plates, as well as $1 \mathrm{~mL}$ was inoculated into $9 \mathrm{~mL}$ of Brucella broth. Fragments of tissues from testes, epididymis and lymph nodes were homogenized in phosphate buffer (PBS) containing amphotericin $\mathrm{B}$ and $1 \mathrm{~mL}$ of homogenate was then transferred into $9 \mathrm{~mL}$ of Brucella broth. All samples were incubated at $37^{\circ} \mathrm{C} \pm 2{ }^{\circ} \mathrm{C}$ with $5-10 \% \mathrm{CO}_{2}$. Twenty-five 
microliter of broth was sown on Brucella Agar every six days, for six weeks to monitor the eventual growth of the pathogen [8].

Colonies attributable to Brucella spp. grew in Brucella agar were subcultured onto blood agar plates for $24-48 \mathrm{~h}$ at $37^{\circ} \mathrm{C}$ in a $10 \% \mathrm{CO}_{2}$ atmosphere. Before further investigation, after 24-48 h, colonies were subcultured onto Brain Heart Infusion Agar (BHI). On isolated strains, Gram staining, growth in MacConkey agar, growth in $\mathrm{CO}_{2}$ atmosphere, oxidase and catalase tests, mobility, urease, and $\mathrm{H}_{2} \mathrm{~S}$ production, glucose oxide fermentation, growth in presence of basic fuchsin and thionin at a final concentration of $50 \mu \mathrm{g} / \mathrm{mL}$ were performed [31].

An agglutination test with Brucella $\mathrm{A}$ and $\mathrm{M}$ anti-serum was carried out. The Brucella polyvalent and monospecific Brucella $\mathrm{A}$ and $\mathrm{M}$ antisera were supplied by the Food and Agriculture Organization/WHO Collaborating Centre for Research on Brucellosis (Veterinary Laboratories Agency, Weybridge, UK). A 4 McFarland suspension of each strain was used to perform phage characterization by Brucella-phage of the Tbilisi (Tb), Weybridge $(\mathrm{Wb})$, and Izatnagar (Iz1) groups [31].

\subsection{Brucella spp. Typing}

Genomic DNA from each strain isolated was extracted using the commercial kit (Purelink Genomic DNA, Invitrogen, Thermo Fisher Scientific, Waltham, MA, USA) following the bacterial culture protocol provided by the manufacturer. Typing was performed with AMOS (Abortus, Melitensis, Ovis, Suis) PCR. AMOS-PCR is a multiplex PCR designed to detect the polymorphism arising from species-specific localization of the insertion sequence IS711 in the chromosome of the four species of Brucella [32,33]. Amplicons were checked after electrophoresis in a $1 \%$ agarose gel.

\section{Conclusions}

This study performed on a B. ovis infected herd showed the clinical and diagnostic profile of the disease. Furthermore, it demonstrates the importance of the synergistic use of different diagnostic approaches that can facilitate the identification of infection. In order to allow faster identification and removal of chronic shedders, each farm should be monitored by a combination of serological tests (I-ELISA and CFT), molecular biology assays (PCR, real-time PCR), and auxiliary tests (genital palpation and seed culture whenever possible). This approach should be carried out at each breeding season, as well as before the introduction of new rams in the flocks.

Therefore, the introduction of Reg. 429/2016 establishes a new approach for proper, shared, and homogeneous veterinary measures in the whole EU against this pathogen which will also concern clinical and diagnostic protocols effective to detect even subclinical infections.

Author Contributions: Conceptualization, G.C.; methodology, P.G., M.A., A.T., A.C., C.P., L.G., L.C., M.T.; formal analysis, P.G., S.M., M.A., A.T., A.C., C.P., L.G., L.C.; investigation, P.G., S.B., M.A., A.T., A.C., C.P., L.G., L.C., H.A.H.; resources, S.C., S.B., H.A.H., G.C.; data curation, P.G., S.M.; writing—original draft preparation, P.G., S.M.; writing—review and editing, P.G., S.M., G.C.; supervision, G.C.; project administration, G.C.; funding acquisition, G.C. All authors have read and agreed to the published version of the manuscript.

Funding: This research was financially supported by the Italian Health Ministry grant number RC IZS SI 08/15.

Institutional Review Board Statement: The study was conducted according to the guidelines of the Declaration of Helsinki, and approved by the Institutional Review Board (or Ethics Committee) of Istituto Zooprofilattico Sperimentale della Sicilia “Adelmo Mirri" (protocol code U/0013035/16, date of approval 14 September 2016).

Informed Consent Statement: Not applicable.

Data Availability Statement: Data are contained within the article. 
Acknowledgments: The authors thank Fabrizio Chiruzzi for graphic support and photo editing. We are also very grateful for the cooperation of the farmer.

Conflicts of Interest: The authors declare no conflict of interest.

\section{References}

1. Olsen, S.C.; Palmer, M.V. Advancement of knowledge of Brucella over the past 50 years. Vet. Pathol. 2014, 51, 1076-1089. [CrossRef]

2. Blasco, J.M. Brucella ovis. In Animal Brucellosis; Nielsen, K., Duncan, J.R., Eds.; CRC Press: Boca Raton, FL, USA, 1990; pp. 351-378.

3. Blasco, J.M. Brucella ovis infection. In Infectious and Parasitic Diseases of Livestock; Lefeòvre, P.C., Blancou, J., Chermette, R., Uilenberg, G., Eds.; Lavoisier: Paris, France, 2010; Volume 2, pp. 1047-1063.

4. Marco, J.; Gonzalez, L.; Cuervo, L.; de Heredia, F.B.; Barberan, M.; Marin, C.; Blasco, J. Brucella ovis infection in two flocks of sheep. Vet. Rec. 1994, 135, 254-256. [CrossRef]

5. Sergeant, E.S. Seroprevalence of Brucella ovis infection in commercial ram flocks in the Tamworth area. N. Z. Vet. J. 1994, 42, 97-100. [CrossRef] [PubMed]

6. Praud, A.; Champion, J.L.; Corde, Y.; Drapeau, A.; Meyer, L.; Garin-Bastuji, B. Assessment of the diagnostic sensitivity and specificity of an indirect ELISA kit for the diagnosis of Brucella ovis infection in rams. BMC Vet. Res. 2012, 8, 68. [CrossRef] [PubMed]

7. Commission Delegated Regulation (EU). 2018/1629 of 25 July 2018 Amending the List of Diseases Set Out in Annex II to Regulation (EU) 2016/429 of the European Parliament and of the Council on Transmissible Animal Diseases and Amending and Repealing Certain Acts in the Area of Animal Health (Animal Health Law); Commission Delegated Regulation (EU): Brussels, Belgium, 2018.

8. OIE (World Organization for Animal Health). Infection with Brucella ovis. In Manual of Diagnostic Tests and Vaccines for Terrestrial Animals; OIE (World Organization for Animal Health): Paris, France, 2016.

9. OIE (World Organisation for Animal Health). Ovine epididymitis (Brucella ovis) in Manual of Diagnostic Tests and Vaccines for Terrestrial Animals; OIE: Paris, France, 2018.

10. Costa, L.F.; Pessoa, M.S.; Guimarães, L.B.; Faria, A.K.; Morão, R.P.; Mol, J.P.; Garcia, L.N.; Almeida, A.C.; Gouveia, A.M.; Silva, M.X.; et al. Serologic and molecular evidence of Brucella ovis infection in ovine and caprine flocks in the State of Minas Gerais, Brazil. BMC Res. Notes. 2016, 9, 190. [CrossRef]

11. Hinić, V.; Brodard, I.; Thomann, A.; Cvetnić, Z.; Makaya, P.V.; Frey, J.; Abril, C. Novel identification and differentiation of Brucella melitensis, B. abortus, B. suis, B. ovis, B. canis, and B. neotomae suitable for both conventional and real-time PCR systems. J. Microbiol. Methods 2008, 75, 375-378. [CrossRef]

12. De Massis, F.; Zilli, K.; Di Donato, G.; Nuvoloni, R.; Pelini, S.; Sacchini, L.; D’Alterio, N.; Di Giannatale, E. Distribution of Brucella field strains isolated from livestock, wildlife populations, and humans in Italy from 2007 to 2015. PLoS ONE. 2019, 14, e0213689. [CrossRef] [PubMed]

13. Buckrell, B.C.; McEwen, S.A.; Johnson, W.H.; Savage, N.C. Epididymitis Caused by Brucella ovis in a Southern Ontario Sheep Flock. Can. Vet. J. 1985, 26, 293-296. [PubMed]

14. Cvetnić, Ž.; Zdelar-Tuk, M.; Duvnjak, S.; Benić, M.; Mihaljević, Ž.; Habrun, B.; Reil, I.; Cvetnić, M.; Spicic, S. Infectious epididymitis caused by Brucella ovis in Croatian sheep flocks. Turk. J. Vet. Anim. Sci. 2017, 41, 679-685. [CrossRef]

15. Farina, R.; Cerri, D.; Andreani, A.; Renzoni, G.; Guadagnini, P.F.; Lombardi, G. Epididymitis in rams: First report of the presence of Brucella ovis in Italy. Sel. Vet. 1995, 36, 285-291.

16. Chiarenza, G.; Villari, S.; Galluzzo, P.; Briganò, S.; Alfano, M.; Tagliarini, A.; Pilato, V.; Guercio, A.; Stancanelli, A. Brucella ovis presence in sicilian farms (Italy). Int. J. Infect. Dis. 2018, 73, 385-386. [CrossRef]

17. Mancuso, G.; Scornaienchi, D.; Pecora, M.; Lucifora, G. Brucella ovis: Indagine sierologica negli allevamenti della provincia di Cosenza. Dati preliminari. Large Anim. Rev. 2004, 10, 4.

18. Elderbrook, M.; Schumaker, B.; Cornish, T.; Peck, D.; Sondgeroth, K. Seroprevalence and risk factors of Brucella ovis in domestic sheep in Wyoming, USA. BMC Vet. Res. 2019, 15, 246. [CrossRef]

19. Van Metre, D.C.; Rao, S.; Kimberling, C.V.; Morley, P.S. Factors associated with failure in breeding soundness examination of Western USA rams. Prev. Vet. Med. 2012, 105, 118-126. [CrossRef] [PubMed]

20. Bagley, C.V.; Paskett, M.E.; Matthews, N.J.; Stenquist, N.J. Prevalence and causes of ram epididymitis in Utah. J. Am. Vet. Med. Assoc. 1985, 186, 798-801.

21. Souza, T.S.; Costa, J.N.; Martinez, P.M.; de Lima, C.C.V.; Araújo, B.R.; Costa Nelto, A.O.; Anunciação, A.V.M.; Almeida, M.d.G.A.R.; Pinheiro, R.R. Seroepidemiological survey for Brucella ovis infection in sheep flocks of semi-arid region in Bahia State, Brazil. Vet. Zootec. 2011, 18 (Suppl. 3), 697-700.

22. Machado, G.; Santos, D.V.; Kohek, I.; Stein, M.C.; Hein, H.E.; Poeta, A.S.; Vidor, A.C.M.; Corbellini, L.G. Seroprevalence of Brucella ovis in rams and associated flock level risk factors in the state of Rio Grande do Sul, Brazil. Prev. Vet. Med. 2015, 121, 183-187. [CrossRef]

23. Blasco, J.M. Brucelosis ovina. Ovis 2002, 82, 113.

24. Petrović, M.; Špičić, S.; Potkonjak, A.; Lako, B.; Kostov, M.; Cvetnić, Ž. First evidence of Brucella ovis infection in ram sin the Pirot Municipality, Serbia. Vet. Italy 2014, 50, 259-268.

25. Picard-Hagen, N.; Berthelot, X.; Champion, J.L.; Eon, L.; Lyazrhi, F.; Marois, M.; Peglion, M.; Schuster, A.; Trouche, C.; GarinBastuji, B. Contagious epididymitis due to Brucella ovis: Relationship between sexual function, serology and bacterial shedding in semen. BMC Vet. Res. 2015, 11, 125. [CrossRef] 
26. EFSA Panel on Animal Health and Welfare (AHAW). Assessment of listing and categorisation of animal diseases within the framework of the Animal Health Law (Regulation (EU) No 2016/429): Ovine epididymitis (Brucella ovis). EFSA J. 2017, 15, 10. [CrossRef]

27. Gaffuri, A.; Garbarino, C.; Carrara, M.; Sala, L.; Bassi, S.; Messa, G.L.; Cerri, D. Regional control program for monitoring and eradication of Brucella ovis in Lombardia region( August 1995-December 1998): Consideration and evaluation of problems faund in its application. Atti. Fe. Me. S. P. Rum. 1999, VII, 99-103.

28. Grilló, M.J.; Marín, C.M.; Barberán, M.; Blasco, J.M. Experimental Brucella ovis infection in pregnant ewes. Vet. Rec. 1999, 144, 555-558. [CrossRef]

29. Vitale, M.; Migliore, S.; La Giglia, M.; Alberti, P.; Di Marco Lo Presti, V.; Langeveld, J.P. Scrapie incidence and PRNP polymorphisms: Rare small ruminant breeds of Sicily with TSE protecting genetic reservoirs. BMC Vet. Res. 2016, 12, 141. [CrossRef] [PubMed]

30. AQIS (Australian Quarantine and Inspection Service), An Analysis of the Disease Risks, Other Than Scrapie, Associated with the Importation of Ovine and Caprine Semen and Embryos from Canada, the USA and Member States of the European Union. Final Report. 2000; 67p. Available online: http://www.agriculture.gov.au/SiteCollectionDocuments/ba/memos/2000/animal/00-038 b.pdf (accessed on 9 September 2021).

31. Morgan, W.J.B.; McCullough, N.B. Genus Brucella Meyer and Shaw. In Bergey's Manual of Determinative Bacteriology, 8th ed.; Buchanan, R.E., Gibbons, N.E., Eds.; Williams \& Wilkins: Baltimore, MA, USA, 1974; pp. 278-282.

32. Bricker, B.J.; Halling, S.M. Differentiation of Brucella abortus bv. 1, 2, and 4, Brucella melitensis, Brucella ovis, and Brucella suis bv. 1 by PCR. J. Clin. Microbiol. 1994, 32, 2660-2666. [CrossRef] [PubMed]

33. Bricker, B.J.; Hallings, S.M. Enhancement of the Brucella AMOS PCR assay for the differentiation of Brucella abortus vaccine strains S19 and RB51. J. Clin. Microbiol. 1995, 33, 1640-1642. [CrossRef] 